\title{
ДОСЛІДЖЕННЯ ТЕХНОЛОГІЇ ЛАЗЕРНОГО ФРЕЗЕРУВАННЯ
}

() М. І. Анякін, д.т.н., доцент, Мехді Наєбі, аспірант, Р. О. Жук, асистент, П. В. Кондрашев, к.т.н., ст. викладач, О. М. Степура, мол.н.с., НТУУ «КПІ», Київ, Україна

В работе рассмотрена технология фрезерования изделий из различных материалов сфокусированным лазерным излучением с модулированной добротностью. Установлено, что на производительность и качество процесса, вместе с режимами обработки прежде всего влияет механизм разрушения заготовки.

Technologies of laser milling of different materials using Q-switched laser systems are presented in this paper. It was established that mechanism of material removal influences significantly the productivity and quality of laser processing.

\section{Постановка проблеми}

Відомо, що лазерне фрезерування матеріалів (ЛФ) займає проміжну ланку між традиційними методами надшвидкого виготовлення виробів (надшвидкісне різання, електророзрядна обробка) та їх виготовленням за допомогою сфокусованого лазерного випромінювання з порошкових (металевих або керамічних) матеріалів [1-4]. На відміну від надшвидкісного різання та електророзрядної обробки, за допомогою ЛФ, з'являється можливість виготовлення різноманітних виробів з будь-яких матеріалів: сталей, кераміки, надтвердих сплавів та інше, що робить вказаний метод привабливим для виготовлення пресових валів, різноманітних кліше, матриць та інше, які використовуються при глибокому друці, виготовленні шпалер і т. д. При цьому, як і при звичайному надшвидкісному різанні та електроіскрової обробці, здійснюється:

- технологія зняття припуску шар за шаром;

- постійне заглиблення в тіло заготівки інструменту (у нашому випадку - сфокусованого потоку лазерного випромінювання, обмеженого умовною каустичною поверхнею, що $є$ в просторі гіперболоїдом обертання що має «малу» робочу ділянку);

- дотримання умови відсутності пересічення тілом інструменту (не робочою його ділянкою) поверхні, що обробляється;

- залежність величини припуску, що «зрізується» від властивостей заготовки та режимів обробки.

\section{Аналіз попередніх} досліджень

Для реалізації технології ЛФ зазвичай використовуються ла- 
зери на алюмо-іттрієвому гранаті (АІГ) $з$ модульованою добротністю (довжина хвилі випромінювання 1,06 мкм) з середньою потужністю випромінювання $\mathrm{P}_{\mathrm{m}}$ та частотою слідування імпульсів $v$, що досягають до 100 Вт та до 50 кГц відповідно [1-4]. Зазначимо, що реалізація технології ЛФ на даному устаткуванні має певну особливість. Так, одиночний імпульс (тривалість $\tau_{\mathrm{P}} 100-$ 500 нс, потужність $\mathrm{P}_{\mathrm{P}}$ до 5 кВт) утворює (шляхом випару) в матеріалі, що обробляється, лунку діаметром 10-200 мкм і глибиною від 1 до 100 мкм. 3 метою підвищення ефективності процесу та зменшення розмірів зони термічного впливу обробку здійснюють на високих швидкостях сканування Vs (50500 мм/с). Слід відмітити, що при збільшенні $v$ зростає середня потужність випромінювання $\mathrm{P}_{\mathrm{m}}$ та, в одночасно зростає $\tau_{\mathrm{P}}$, що веде до зниження пікової потужності імпульсу $\mathrm{P}_{\mathrm{p}}$. Зняття заданого шару матеріалу (згідно з керуючою програмою) здійснюють шляхом накладання окремих плям фокусування 3 певним коефіцієнтом їх перекриття, які утворюють окрему доріжку, а самі доріжки накладають одну на одну (типова відстань між ними 5-10 мкм) 3 певним кроком Step $_{\text {ox. }} 3$ метою підвищення продуктивності операції, що виконується, автори [2] пропонують вести обробку постійно змінюючи кут нахилу окремих доріжок. В даному випадку, гарантується зменшення шорсткості обробленої поверхні та вдається збільшити відстань між окремими доріжками від 10 до 20 мкм.

\section{Мета роботи}

Метою даної роботи є дослідження технології ЛФ матеріалів, які мають різний механізм руйнування та пошук шляху підвищення ефективності операції, що виконується.

\section{Результати проведених досліджень}

Дослідження проводилися на експериментальному лазерному устаткуванні [4] у складі лазерів на АІГ з модульованою добротністю $\left(\mathrm{P}_{\mathrm{m}}\right.$ в одномодовому режимі генерації від 3 до 50 Вт), які забезпечені сервісним устаткуванням (рис. 1). Переміщення сфокусованого випромінювання по поверхні зразків здійснювали 2-х координатною системою сканування RAZORSCAN-15 із змінними об'єктивами. У якості зразків використовували заготовки із сплаву ВК8, сталі 65Г, кубічного нітриду бору, конструкційної кераміки на основі карбіду кремнію. В процесі досліджень змінювалася швидкість сканування Vs крок між доріжками Stepox та v. Природно, при зміні Vs i v змінювалися як відстані Step оү між окремими плямами радіусу $r_{\mathrm{p}}$ так і коефіцієнт їх перекриття. У кожній експериментальній точці досліди дублювали 3 рази. Вимірювання результатів взаємодії сфокусованого лазерного випромінювання 3 матеріалами (глибина обробки Н i висота мікронерівностей $\mathrm{Rz}$ ) 
проводили за допомогою інструментального мікроскопа БMІ-1Ц, подвійного мікроскопа Лінника МІC-11.

Попередні дослідження технології вели за допомогою обчислювальних експериментів. У якості моделі процесу використовували багатовимірне нелінійне нестаціонарне рівняння теплопровідності 3 нелінійною схемою врахування фазових переходів, яке, замінювалось кінцево-різницевим аналогом та вирішувалось методом прогонки.

Так, на рис. 2, 3 приведено результати розрахунку взаємодії сфокусованого лазерного випромінювання (на різних режимах обробки) зі зразками 3 твердого сплаву ВК8 та ельбору. При рівних режимах обробки результат дії лазерного випромінювання відрізняється, що пояснюється різними теплофізичними властивостями матеріалів, які обробляються. Слід зазначити, що в процесі лазерного нагріву сплаву ВК8 відбувається ряд перетворень. Так, при температурі 1494 으 відбувається плавлення зв'язки (Со), надалі, при температурі 2720 ॰ С відбувається плавлення і дисоціація WC. Потім, із зростанням кількості енергії, що поступає, і відповідно температури, відбувається плавлення W i випаровування Со і, нарешті випаровування самого вольфраму. На відміну від твердого сплаву BK8, нагрів надтвердого матеріалу на основі кубічного нітриду бору, має певні відмінності. Так, при атмосферному тиску навколишньої атмо-

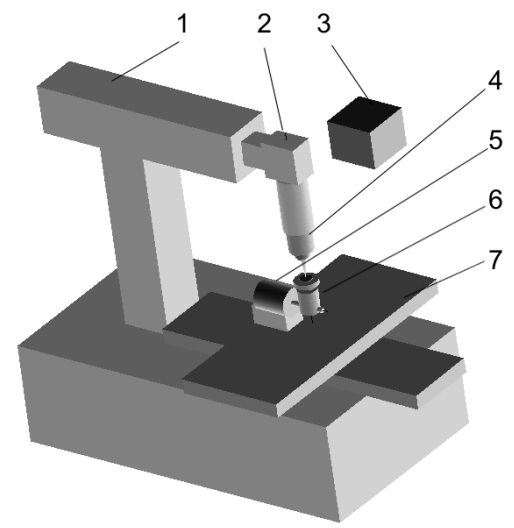

Рис. 1. Схема експериментального устаткування, де: 1 - випромінювач, 2 - поворотна система;

3 - система сканування; 4 - рухомий об'єктив; 5 - шпиндель;

6 - обертач; 7 - рухомий стіл

сфери, при нагріві (температура 2700-3000 ㄷ) ельбор розкладається в гексагональний нітрид бору (порошок), який (у свою чергу) при подальшому нагріві розкладається на бор і азот, що значно полегшує його лазерну обробку. Порівнюючи результати розрахунків з експериментальними даними (рис. 4-6) слід відмітити, що продуктивність та якість обробки ельбору перевищує аналогічні показники обробки надтвердого сплаву ВК8. Вказане можна пояснити не тільки різницею в теплофізичних властивостях матеріалів, що обробляються, але й в механізмі їх руйнування. Так, при обробці металевих матеріалів, як відмічено [2, 3] в процесі нагріву (у зоні дії лазерного випромінювання) оброблюваний матеріал, який обробляється, зазнає структурні і фазові перетворення. Частина рідкої фази, що утворилася, під дією пару плазми, ударних 


\section{ТЕХНОЛОГІЧН І ПРОЦЕСИ}
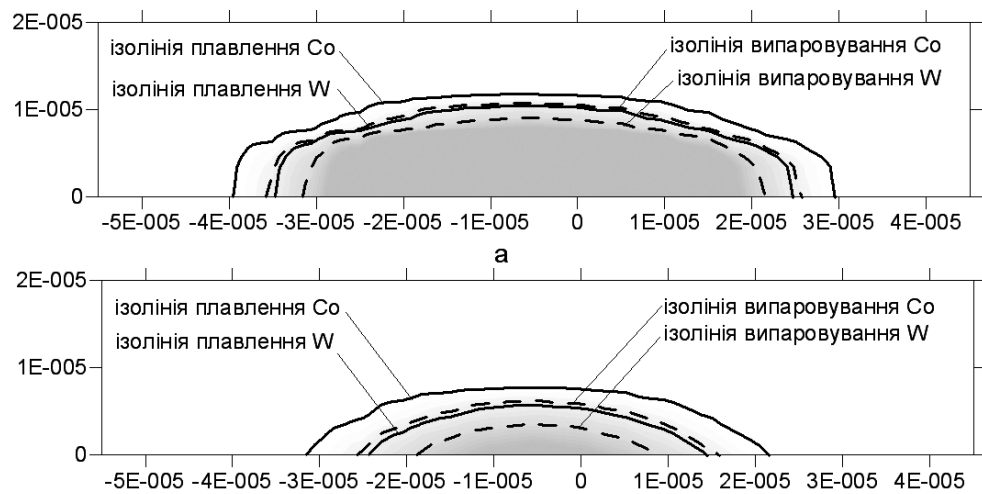

6

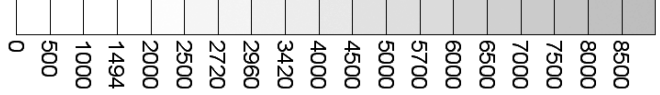

Рис. 2. Розподіл температур у сплаві ВК8, який виникає під час дії лазерного випромінювання $\left(r_{\mathrm{P}}=0,025 \mathrm{Mm}, \mathrm{Vs}=50 \mathrm{~mm} / \mathrm{c}\right)$ з різними режимами генерації, де: $\mathrm{a}-\mathrm{P}_{\mathrm{P}}=2,45 \cdot 10^{4} \mathrm{BT}, \tau_{\mathrm{P}}=150 \mathrm{нc}, \nu=3 \mathrm{\kappa}$ ц; б $-\mathrm{P}_{\mathrm{P}}=1,17 \cdot 10^{4}$

$\mathrm{BT}, \tau_{\mathrm{P}}=480 \mathrm{Hc}, v=50$ кГц; в - масштаб температур
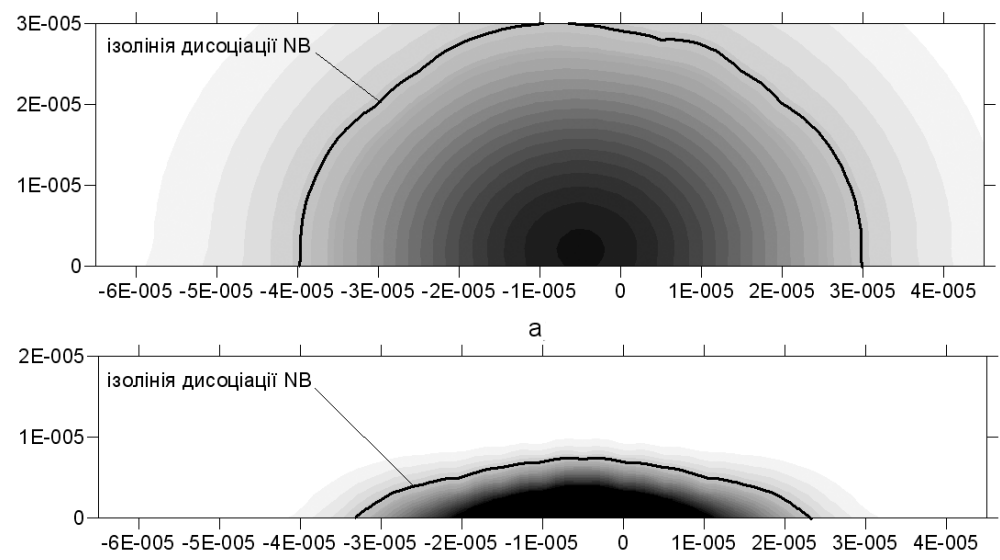

б

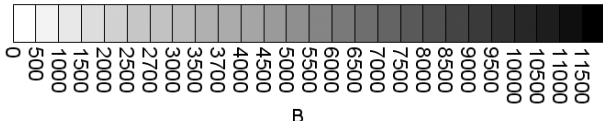

Рис. 3. Розподіл температур у ельбору, який виникає під час дії лазерного випромінювання $\left(r_{\mathrm{P}}=0,025 \mathrm{Mm}, \mathrm{Vs}=50 \mathrm{~mm} / \mathrm{c}\right)$ з різними режимами генерації, де: $\mathrm{a}-\mathrm{P}_{\mathrm{P}}=2,45 \cdot 10^{4} \mathrm{BT}, \tau_{\mathrm{P}}=150 \mathrm{Hc}, v=3$ кГц; б $-\mathrm{P}_{\mathrm{P}}=1,17 \cdot 10^{4} \mathrm{BT}$, $\tau_{\mathrm{P}}=480 \mathrm{HC}, v=50$ кГц; в - масштаб температур

хвиль, викидається 3 лунки, що утворилася, і частково осідає на прилеглій ділянці. Якщо у випадку лазерного свердлення от- ворів, скрайбування, різання можна спостерігати певну симетрію в розташуванні рідкої фази навколо місця дії сфокусо- 

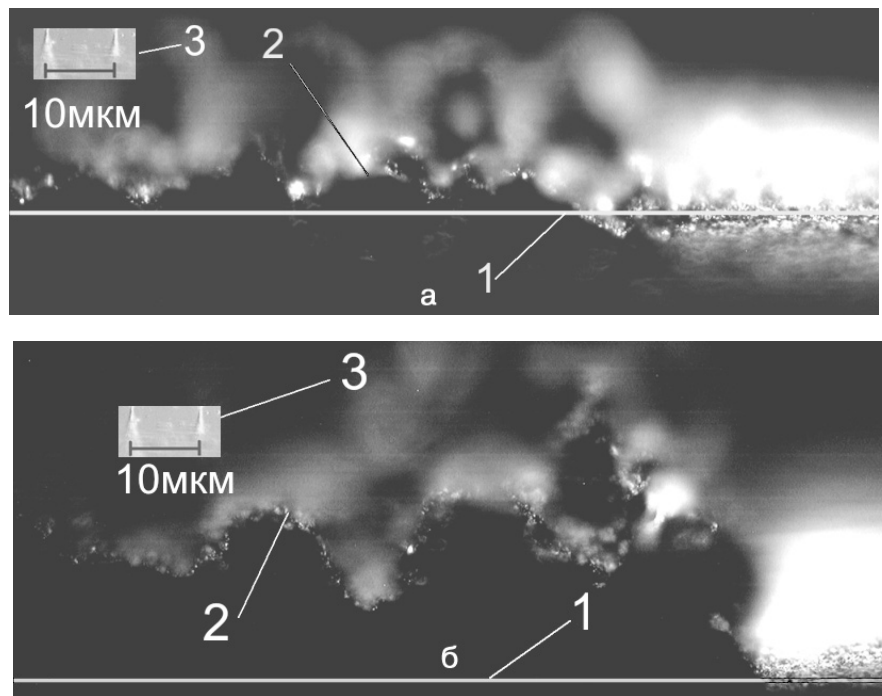

Рис. 4. Профіль поверхні зразків з сплаву ВК8 (а) та ельбору (б) утворені при обробці сфокусованим лазерним випромінюванням з $\mathrm{r}_{\mathrm{P}}=0,025 \mathrm{Mм}$,

$V s=50 \mathrm{~mm} / \mathrm{c}$, Step $_{\mathrm{OX}}=20 \mathrm{m \kappa M}, \mathrm{P}_{\mathrm{P}}=2,45 \cdot 10^{4} \mathrm{BT}, \tau_{\mathrm{P}}=150 \mathrm{\mu c}, \nu=3 \mathrm{\kappa} Г ц$
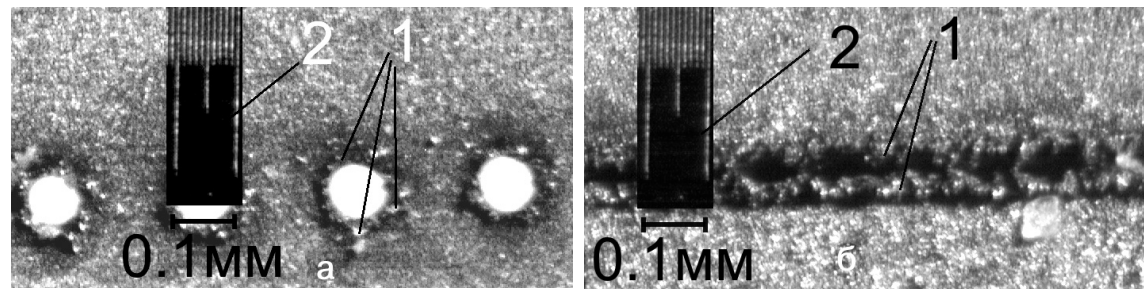

Рис. 5. Отвори (а) та скрайб (б) у пластині ВК8 утворені сфокусованим лазерним випромінюванням, де: 1 - застиглі каплі розплаву; 2 - масштаб

ваного випромінювання (рис. 5), то у випадку ЛФ (коли окремі доріжки накладаються одна на одну з певним кроком), витиснена рідка фаза спотворює не лише оброблювану поверхню, але і вже оброблену ділянку (рис. 4, а), яку знов необхідно обробляти (рис. 6).

При ЛФ матеріалів, які в процесі обробки сфокусованим лазерним випромінюванням 3 модульованою добротністю мають повний цикл: нагрів плавлення-випаровування-застигання рідкої фази-охолодження, зменшення шорсткості обробленої поверхні до- сягається шляхом зменшення потужності окремого імпульсу, що досягається збільшенням частоти модуляції (рис. 7, а). Причому зменшується глибина припуску, який зрізується (рис. 7, б). Як показали дослідження, при рівних відстанях між плямами фокусування Step oy (досягається за рахунок зміни швидкості сканування), в усіх випадках глибина Н обробки більша при низькій частоті модуляції, але величина окремих мікронерівностей значно перевищує аналогічні показники при обробці на високій v. 


\section{ТЕХНОЛОГІЧНІ ПРОЦЕСИ}

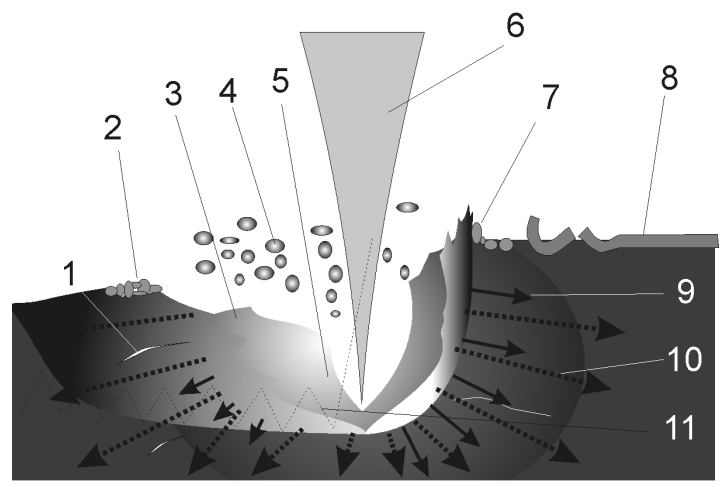

Рис. 6. Схема утворення мікронерівностей при лазерному фрезеруванні поверхні, де: 1 - мікротріщини; 2 - «бризки» розплаву, що осіли;

3 - застиглий розплав; 4 - краплі розплаву; 5 - розплавлений метал;

6 - лазерний імпульс; 7 - пульсація поверхні за рахунок ударної хвилі;

8 - пошкоджене покриття; 9 - ударна хвиля; 10 - зона термічного впли-

ву; 11 - профіль поверхні, яка повинна утворитись
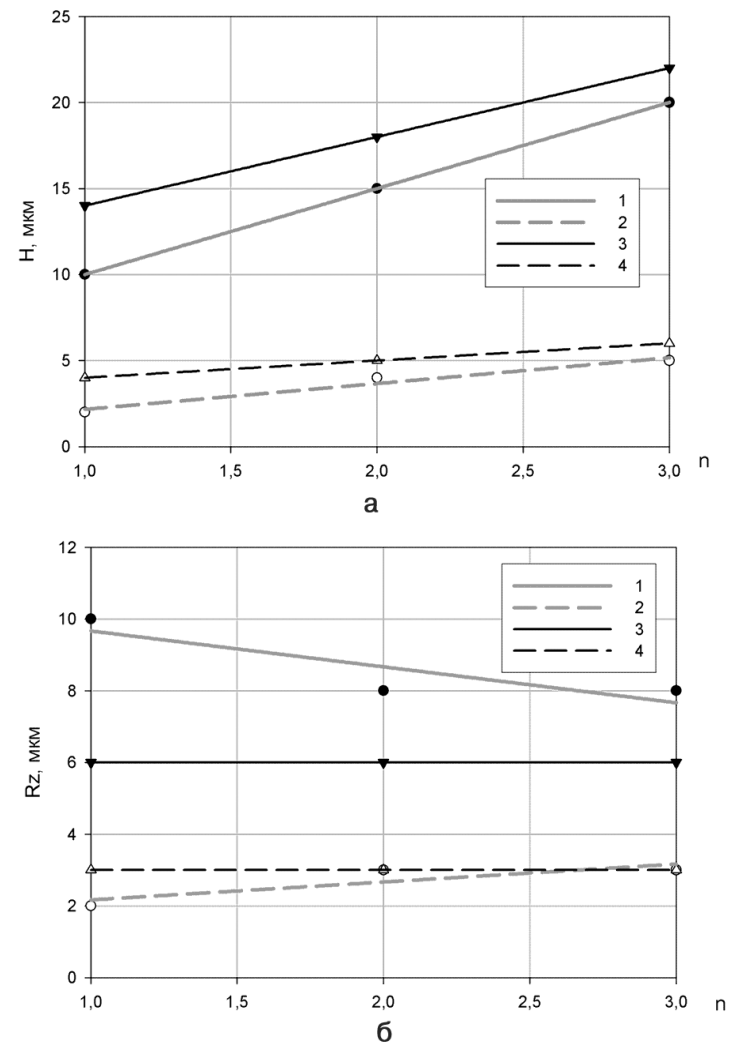

Рис. 7. Залежності глибини обробки (а) та шорсткості обробленої поверхні

(б) у зразка з ВК8 від кількості проходів лазерного випромінювання $v$ де:

1 - частота слідування імпульсів $v=3$ кГц, крок між доріжками Step $_{\mathrm{OX}}=20$ мкм; $2-v=40$ кГц; Step Ox $=20$ мкм; $3-v=3$ кГц;

$$
\text { Step }{ }_{\mathrm{OX}}=5 \text { мкм; } 4-v=40 \text { кГц; Step }
$$


у випадку обробки матеріалів, які в процесі ЛФ (на аналогічних попереднім режимах) руйнуються без утворення рідкої фази (наприклад природній або штучний алмаз, кубічний нітрид бору та інш.), або її кількість мінімальна (наприклад конструкційна кераміка на основі карбіду кремнію) спостерігаються залежності глибини обробки та шорсткості поверхні від режимів обробки аналогічні наведеним, проте (як відмічалось раніше) продуктивність та якість обробки значно вищі. Так, на рис. 8 наведено залежності глибини ЛФ та шорсткості утвореної поверхні ельбору від режимів обробки.

Ще однією ілюстрацією залежності продуктивності і якості обробки від механізму руйнування матеріалу заготовки є наведені на рис. 9 зображення профілів оброблених поверхонь зразків зі сталі 65Г та 3 конструкційної кераміки на основі карбіду кремнію, що отримані на однакових режимах обробки. Як видно, 3 рис. 9
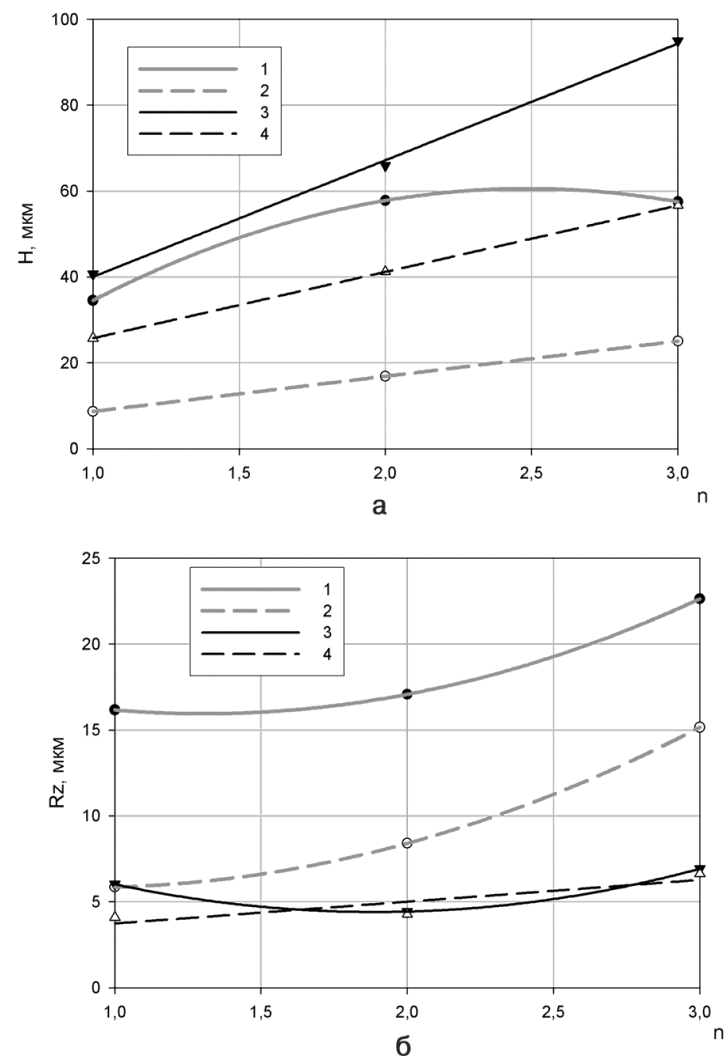

Рис. 8. Залежності глибини обробки (а) та шорсткості обробленої поверхні

(б) у зразка з ельбору від кількості проходів лазерного випромінювання $\mathrm{n}$ де: 1 - частота слідування імпульсів $v=3$ кГц, крок між доріжками

Step $_{\mathrm{OX}}=20$ мкм; $2-v=40$ кГц; StepOX = 20 мкм; $3-v=3$ кГц;

$$
\text { StepOX = } 5 \text { мкм; } 4-v=40 \text { кГц; Step ох }=5 \text { мкм }
$$



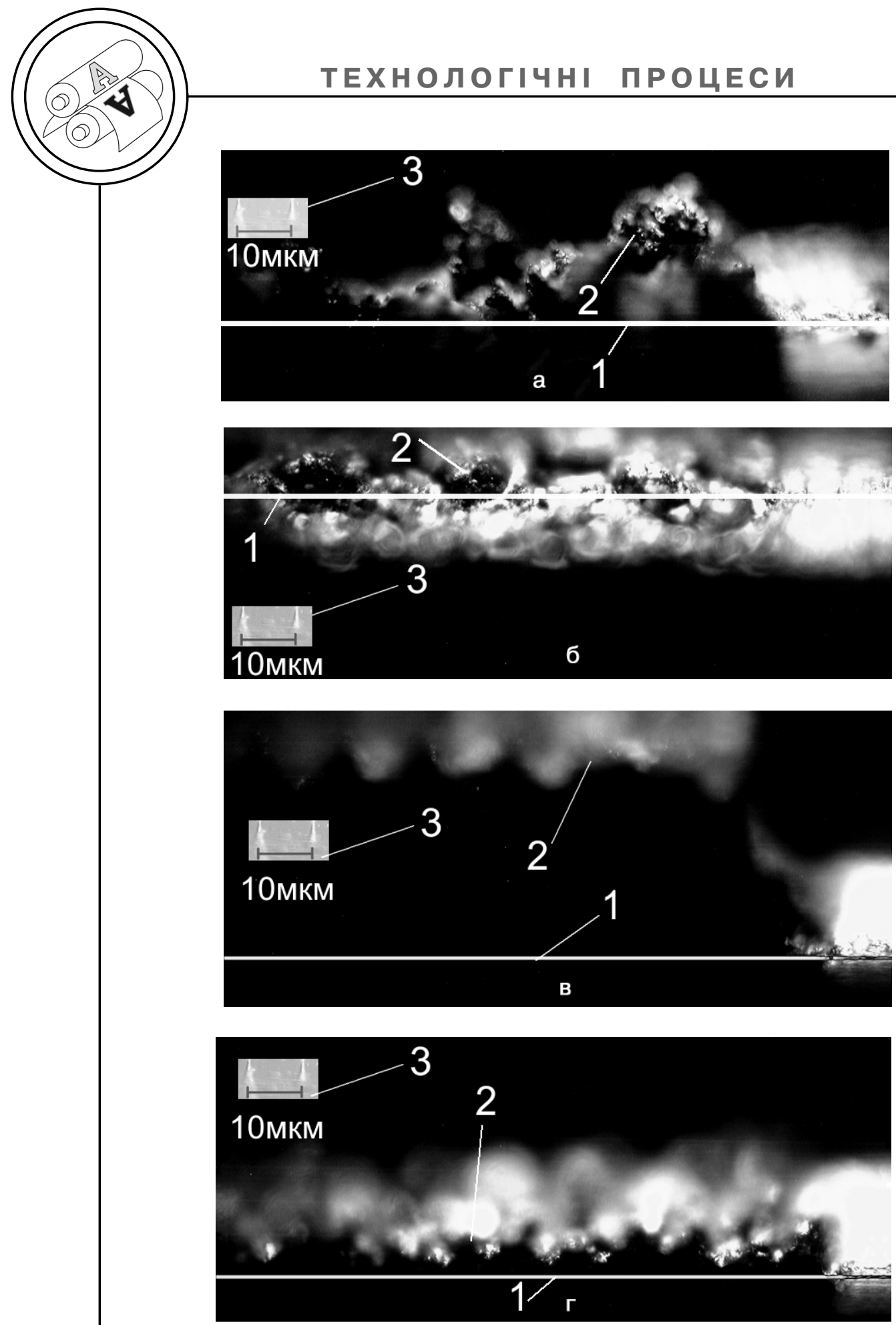

Рис. 9. Профіль поверхні зразків зі сталі 65Г (а, б) та конструкційної кераміки (в, г) утворені при обробці сфокусованим лазерним випромінюванням з $\mathrm{r}_{\mathrm{P}}=0,025 \mathrm{~mm}, \mathrm{Vs}=50 \mathrm{~mm} / \mathrm{c}$, Step $\mathrm{OX}=20$ мкм, причому a, в $-v=3$ кГц, б, г-v $=40$ кГц 


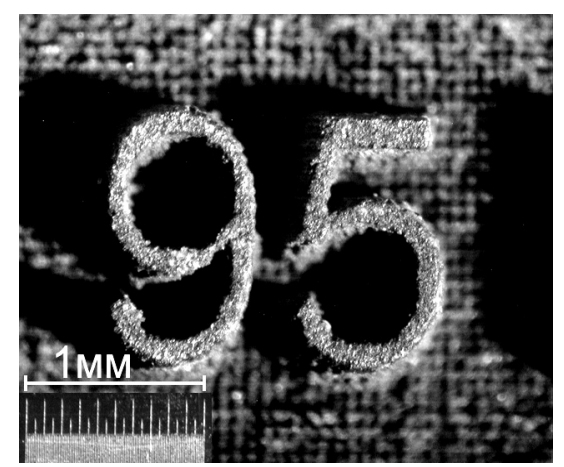

a

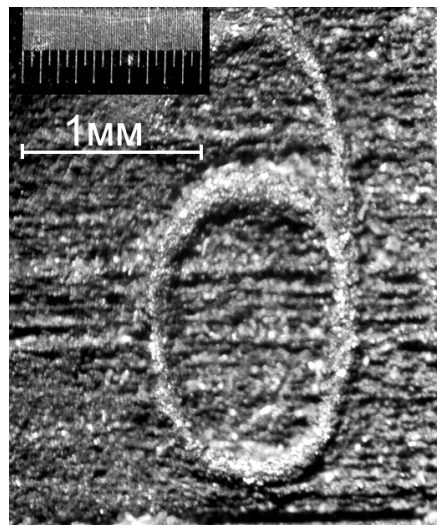

б

Рис. 10. Зовнішній вигляд матриць з нітриду бору (а) та твердого сплаву BК8 (б) отриманих за допомогою сфокусованого лазерного випромінювання

профіль поверхні сталі 65Г подібний профілю поверхні сплаву ВК8, тобто не контрольована рідка фаза, яка утворилась під час випаровування металу спотворює поверхню, яка вже оброблена, а при обробці конструкційної кераміки на основі карбіду кремнію профіль поверхні повторює траєкторію руху сфокусованого променя та має «регулярний» рельєф. Причому, зменшуючи крок між доріжками Step ox, як і при обробці ельбору (рис. 8) ми зменшуємо величину шорсткості обробленої поверхні та збільшуємо глибину обробки.

Зазначимо, що знання залежностей глибини ЛФ від технологічних параметрів (рис. 7, 8), дозволяе вирахувати крок заглиблення фокальної площини оптики, що фокусує випромінювання в тіло заготовки, забезпечуючи тим самим постійне взаємне положення каустичної поверхні (яка огинає сфокусоване лазерне випромінювання) та поверхні, що обробляється. В даному випадку ми забезпечуємо наперед задане зняття припуску, тобто забезпечуємо стабільність та якість операції, що виконується. Так, на приклад, на рис. 10 наведені фрагменти матриць для тиснення з ельбору (рис. 10, а) та сплаву ВK8 (рис. 10, б), які утворені при обробці на однакових режимах (крок між доріжками 20 мкм). Зазначимо, після кожного другого проходу сфокусованого випромінювання по зразку з ельбору, він підіймався на 60 мкм (рис. 8, а), що при 40 проходах сфокусованого випромінювання склало загальну глибину обробки 1,2 мм.

\section{Висновки}

В результаті проведених досліджень встановлено:

1. Одним з головних чинників, які впливають на результат фрезерування виробів сфокусова- 
ним випромінюванням лазерів на алюмо-іттрієвому гранаті 3 модульованою добротністю $є$ не тільки режими обробки та теплофізичні властивості матеріалів які обробляються, але й механізм їх руйнування.
2. При рівних умовах обробки, мінімальна шорсткість обробленої поверхні спостерігається у матеріалів, руйнування яких відбувається без утворення рідкої фази, або коли її кількість мінімальна.

1. Kuhl M. From Macro to Micro - The development of laser ablation / M. Kuhl // Proceedings of 21 International Congress on Applications of Lasers \& Electro-optics «ICALEO'2002» Scottsdale, Arizona, USA, Oct. 2002 [Електронний ресурс] / LIA - 2002. - 1 електрон. опт. диск (CD-ROM) ; 12 см. - Систем. вимоги : Pentium ; 32 Mb RAM ; Windows 95, 98, 2000, XP. - Назва 3 контейнера. 2. Vasco J. C. Processing Conditions of Laser Micro-Milling / J. C. Vasco, P. J. Bartolo // Proceedings of The 15th International Symposium On Electromachining, April 23-27, 2007, Pittsburgh, Pennsylvania. - 2007. P. 427-432. 3. Leong K. Drilling with Laser / K. Leong // Industrial laser solutions for manufacturing. - 2000. - 15(9). - P. 39-45. 4. Anyakin N. I. Machining of Shaped Holes Using Focused Laser Radiation / N. I. Anyakin, M. Naebi, and V. S. Kovalenko // Surface Engineering and Applied Electrochemistry. 2012. - Vol. 48. - No. 1. - P. 22-27.

1. Kuhl M. From Macro to Micro - The development of laser ablation / M. Kuhl // Proceedings of 21 International Congress on Applications of Lasers \& Electro-optics «ICALEO'2002», Scottsdale, Arizona, USA, Oct. 2002 [Elektronnij resurs] / LIA - 2002. - 1 elektron. opt. disk (CD-ROM) ; 12 sm. - Sistem. vimohi : Pentium ; 32 Mb RAM ; Windows 95, 98, 2000, XP. - Nazva z kontejnera. 2. Vasco J. C. Processing Conditions of Laser Micro-Milling / J. C. Vasco, P. J. Bartolo // Proceedings of The 15th International Symposium On Electromachining, April 23-27, 2007, Pittsburgh, Pennsylvania. - 2007. P. 427-432. 3. Leong K. Drilling with Laser / K. Leong // Industrial laser solutions for manufacturing. - 2000. - 15(9). - P. 39-45. 4. Anyakin N. I. Machining of Shaped Holes Using Focused Laser Radiation / N. I. Anyakin, M. Naebi, and V. S. Kovalenko // Surface Engineering and Applied Electrochemistry. 2012. - Vol. 48. - No. 1. - P. 22-27. 